\title{
A Broadband High-Gain Printed Antenna Array Using Dipole and Loop Patches for 5G Communication Systems
}

\author{
Yuanzhi Liu, Mustapha C.E. Yagoub \\ University of Ottawa, \\ Ottawa, K1N 6N5 \\ Canada
}

Received: February 28, 2021. Revised: March 22, 2021. Accepted: April 1, 2021. Published: April 5, 2021.

\begin{abstract}
A broadband and high-gain printed antenna array is presented in this paper. Its single antenna element consists of a loop and two symmetric dipole patches, making the element exhibiting broad impedance bandwidth and improved gain at the targeted frequency, which is $28 \mathrm{GHz}$, one of the $5 \mathrm{G} \mathrm{mm}$-wave band, for this design. An $8 \times 3$ antenna array fed by a microstrip line feed network was designed and simulated. With a compact size of $98 \times 32.5 \mathrm{~mm}^{2}$, the array presents a broad $-10 \mathrm{~dB}$ impedance bandwidth of $6.8 \mathrm{GHz}(24.3 \%)$ and a high gain of $18 \mathrm{dBi}$ at $28 \mathrm{GHz}$. Besides, the single-layered array also features low profile, simple geometry, and low cost, making it a good candidate for $5 \mathrm{G}$ communication systems.
\end{abstract}

Keywords-Printed antenna array, loop, dipole, 5G, mm-wave, single-layered.

\section{INTRODUCTION}

$\mathrm{I}$ is well known that the fifth-generation (5G) wireless networks are the proposed next telecommunication standards that based on millimeter-wave (mm-wave) communications due to the shortage of frequency spectrum in microwave bands [1]. Despite that the mm-wave bands can realize high-speed transmission [2], the Friis' transmission equation reveals that the high pass loss is a major shortcoming of mm-wave communications [3]. To address the challenge, antenna arrays with pencil beams, i.e., high gain, are widely implemented in $5 \mathrm{G}$ communication systems [4]-[5].

In recent years, several $5 \mathrm{G} \mathrm{mm-wave} \mathrm{antenna} \mathrm{arrays} \mathrm{have}$ been proposed. In [7], the authors presented a compact $2 \times 2$ slot antenna array operating at $28 \mathrm{GHz}$ that exhibits a moderate gain of $9.6 \mathrm{dBi}$ but with a narrow $-10 \mathrm{~dB}$ fractional impedance bandwidth of $5.7 \%$. [8] presents a $28 \mathrm{GHz}$ high gain patch antenna array with 30 elements. The $102 \times 96.5 \mathrm{~mm}^{2}$ array exhibits a peak gain of around $22 \mathrm{dBi}$, but a fractional bandwidth of only $8.2 \%$. Another mm-wave microstrip patch antenna array presented in [9] has a peak gain of $14.6 \mathrm{dBi}$, but it also exhibits a narrow fractional bandwidth of only $5.4 \%$.

In general, for antenna arrays, high gain can be easily achieved by simply increasing the number of elements and the size of the array as described in [8]. However, the number of elements cannot be infinitely increased due to the losses raised from discontinuities in the feed network, particularly in high frequencies [10], [11]. On the other side, the gain of arrays will be improved without increasing the array size or the losses from the feed network if the gain of antenna elements can be improved. Besides, the bandwidth of an array can be broadened by some complex techniques such as those introduced in [12]. But antenna arrays that exhibit high gain and wide bandwidth usually do not have simple geometries.

In this paper, based on the authors previous work [10], an $8 \times 3$ printed antenna array with broad bandwidth and high gain is proposed. Dipole and loop patches were adopted to design the antenna element, which improves the gain and bandwidth performance of the element. Simulated in the Ansys-HFSS[13] commercial software, the array exhibits a broad $-10 \mathrm{~dB}$ impedance bandwidth of $6.8 \mathrm{GHz}$ and a high gain of $18 \mathrm{dBi}$ at $28 \mathrm{GHz}$, its targeted frequency in this design. Despite its good performance, the array also has some other attractive features such as compactness, low profile, simple geometry, etc.

\section{ANTENNA ELEMENT DESIGN AND Discussions}

\section{A. Configuration}

The antenna element consists of a loop and two dipoles, 
which has been described in the authors previous work [10]. Its configuration is shown in Fig. 1, the rectangular loop works as a radiator as well as a power divider to feed dipoles. The element is printed on the Rogers RO4003 laminate with relative permittivity of 3.55 , dielectric loss tangent of 0.0027 , and thickness of $0.203 \mathrm{~mm}$.

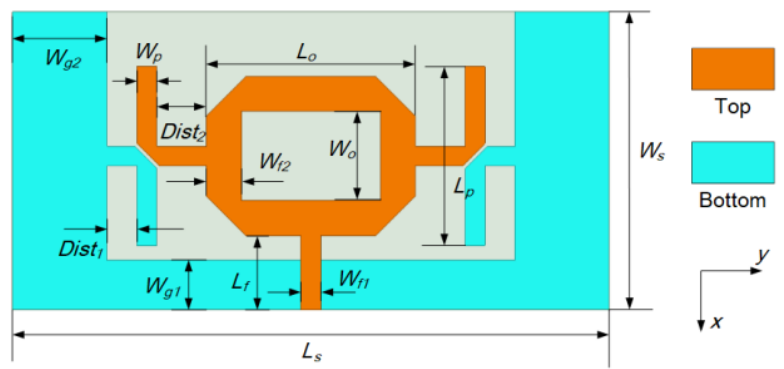

Fig. 1. Configuration of the presented antenna. $\left(L_{f}=1.5 \mathrm{~mm}, L_{s}=12 \mathrm{~mm}, L_{p}=\right.$ $3.6 \mathrm{~mm}, L_{o}=4.2 \mathrm{~mm}, W_{s}=6 \mathrm{~mm}, W_{f 1}=0.4 \mathrm{~mm}, W_{f 2}=0.7 \mathrm{~mm}, W_{o}=1.8 \mathrm{~mm}$, $W_{g l}=1 \mathrm{~mm}, W_{g 2}=1.9 \mathrm{~mm}, W_{p}=0.4 \mathrm{~mm}$, Dist $_{1}=0.7 \mathrm{~mm}$, Dist $\left._{2}=1 \mathrm{~mm}\right)$

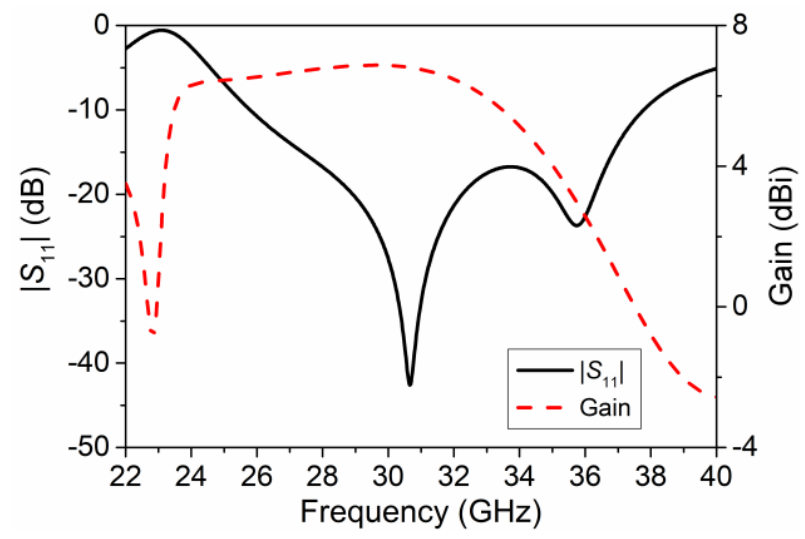

Fig. 2. $\left|S_{11}\right|$ and gain of the proposed antenna element.

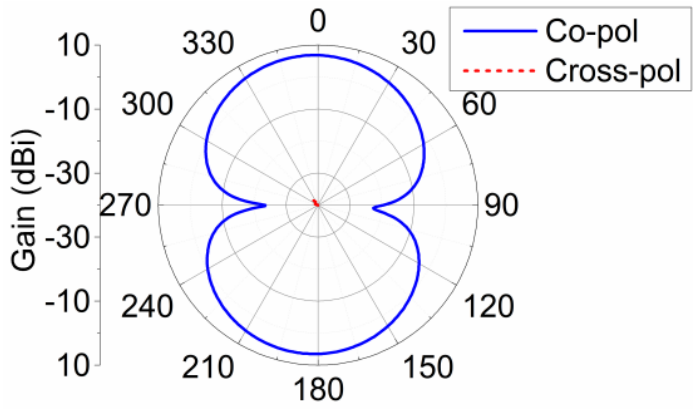

(a).

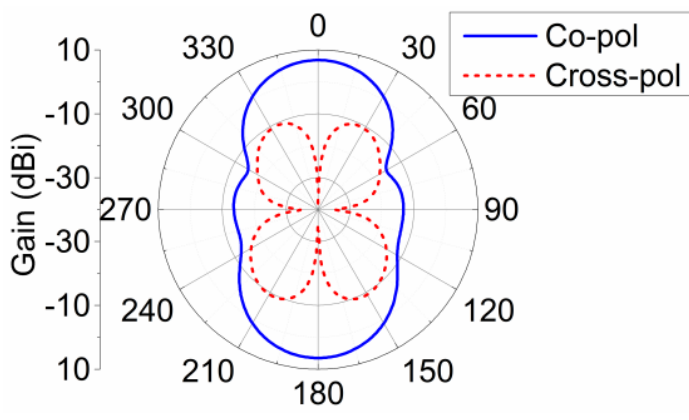

(b).

Fig. 3. Radiation patterns of the presented antenna at $28 \mathrm{GHz}$. (a). $x z$-plane and (b). $y z$-plane

\section{B. Performance}

The antenna element has a $-10 \mathrm{~dB}$ impedance bandwidth of $12 \mathrm{GHz}(25.8-37.8 \mathrm{GHz})$, i.e., a fractional bandwidth of $42.9 \%$ as shown in Fig. 2. Besides, its gain is stable and has an average value of $6.5 \mathrm{dBi}$ in the frequency range of $24-32 \mathrm{GHz}$, but it decreases sharply beyond the frequency range mainly due to mismatch loss and deformation of the radiation pattern.

Fig. 3 shows the radiation patterns of the element. It presents directional radiation patterns with a peak gain of $6.8 \mathrm{dBi}$ at 28 $\mathrm{GHz}$ and a low cross polarization level especially at $x z$-plane. More surprisingly, the size of the antenna is only $12 \times 6 \mathrm{~mm}^{2}$ due to the proper arrangement of the loop patch and the dipole patches. In fact, achieving such a high gain with $1.12 \lambda_{0} \times 0.56 \lambda_{0}$ is satisfying.

\section{ANTENNA ARRAY DESIGN AND DISCUSSIONS}

\section{A. Configuration}

Fig. 4 shows the configuration of the proposed $8 \times 3$ planar array. Fed by a microstrip line feed network, the size of the array is only $98 \mathrm{~mm} \times 32.5 \mathrm{~mm}$. The 24 elements are fed uniformly and in phase.

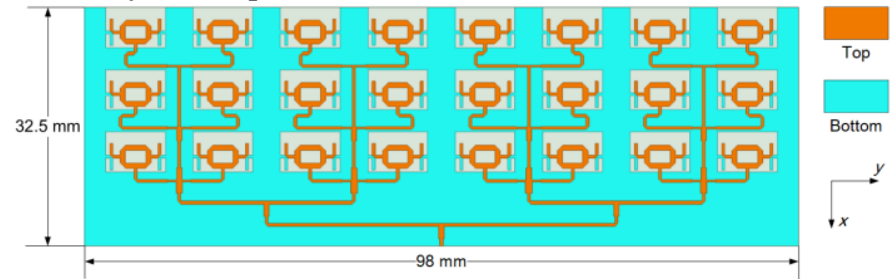

Fig. 4. Configuration of the proposed antenna array.

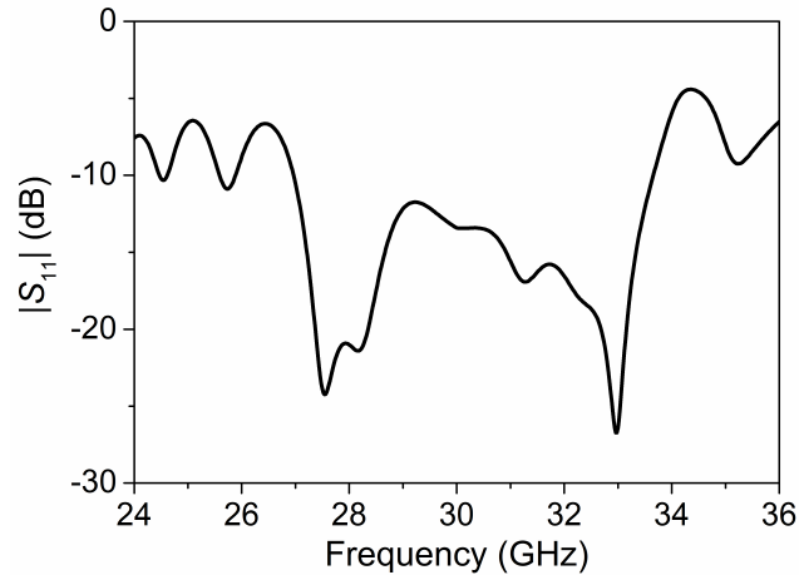

Fig. 5. $\left|S_{11}\right|$ of the proposed antenna array.

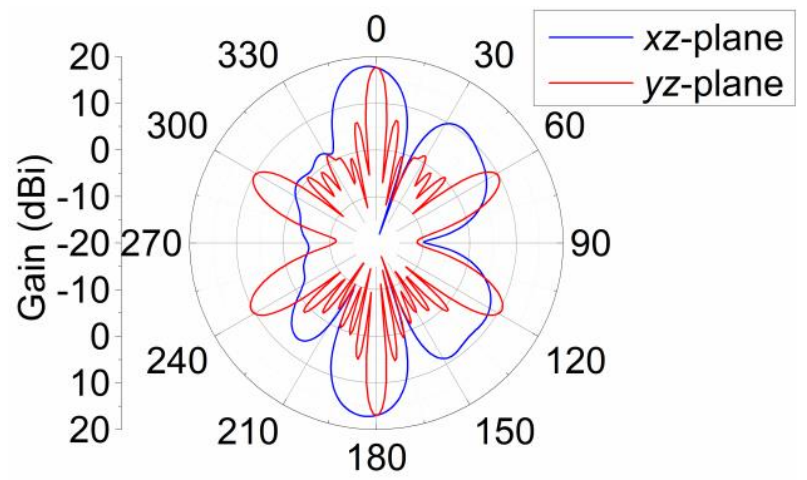

Fig. 6. Radiation patterns of proposed antenna array at $28 \mathrm{GHz}$. 
TABLE I. COMPARISON OF ANTENNA ARRAYS OPERATING AT $28 \mathrm{GHz}$

\begin{tabular}{|c|l|l|l|l|l|}
\hline \multirow{2}{*}{ Works } & \multicolumn{5}{|c|}{ Key Parameters } \\
\cline { 2 - 6 } & $\begin{array}{c}\text { Impedance } \\
\text { Bandwidth } \\
(\mathbf{G H z})\end{array}$ & $\begin{array}{c}\text { Peak } \\
\text { Gain } \\
(\mathbf{d B i})\end{array}$ & $\begin{array}{c}\text { Size } \\
\left(\mathbf{m m}^{2}\right)\end{array}$ & $\begin{array}{c}\text { Numbers } \\
\text { of } \\
\text { Elements }\end{array}$ & Complexity \\
\hline$[7]$ & 1.6 & 9.5 & $36.5 \times 32$ & $2 \times 2$ & Moderate \\
\hline$[8]$ & 2.3 & 22 & $96.5 \times 102$ & $5 \times 6$ & Moderate \\
\hline$[9]$ & 1.5 & 14.6 & $78.5 \times 42$ & $4 \times 4$ & Low \\
\hline$[12]$ & 8 & 12 & - & $2 \times 2$ & High \\
\hline$[14]$ & 1.5 & 12 & $17.3 \times 67.1$ & $1 \times 8$ & Low \\
\hline$[15]$ & 0.5 & 9.2 & - & $2 \times 2$ & Moderate \\
\hline $\begin{array}{c}\text { This } \\
\text { work }\end{array}$ & $\mathbf{6 . 8}$ & $\mathbf{1 8}$ & $\mathbf{9 8 \times 3 2 . 5}$ & $\mathbf{3} \times \mathbf{8}$ & Low \\
\hline
\end{tabular}

\section{B. Performance}

Fig. 5 shows that the array has a $-10 \mathrm{~dB}$ impedance bandwidth of $6.8 \mathrm{GHz}(26.9-33.7 \mathrm{GHz})$, i.e., fractional impedance bandwidth of $24.3 \%$. The radiation patterns (Fig. 6) illustrate that the gain and the sidelobe level of the array is 18 $\mathrm{dBi}$ and $-8 \mathrm{~dB}$ at $28 \mathrm{GHz}$, respectively.

\section{Comparison with Existing Mm-wave Antenna Arrays}

In Table I, the proposed design performance is successfully compared to several existing works of antenna arrays operating at $28 \mathrm{GHz}$. The $2 \times 2$ slot array presented in [7] has a gain of 9.5 $\mathrm{dBi}$ and a narrow bandwidth of $1.6 \mathrm{GHz}$. The antenna array proposed in [8] is a microstrip patch antenna array. With 30 elements, it has a high gain of $22 \mathrm{dBi}$ but at the expense of a large size of $96.5 \times 102 \mathrm{~mm}^{2}$ and a narrow bandwidth. Similarly, the microstrip patch antenna array presented in [9] has a high gain of $14.6 \mathrm{dBi}$ but along with a large size of $78.5 \times 42 \mathrm{~mm}^{2}$ and a narrow bandwidth of $1.5 \mathrm{GHz}$. With a complex structure and a large size, the circular polarized antenna array presented in [12] achieved a wide bandwidth of $8 \mathrm{GHz}$ and a gain of $12 \mathrm{dBic}$ at $28 \mathrm{GHz}$. In [14], a $1 \times 8$ linear array with a moderate gain of 12 $\mathrm{dBi}$ and a narrow bandwidth of $1.5 \mathrm{GHz}$ is presented. The substrate integrated waveguide patch antenna array presented in [15] exhibits only $0.5 \mathrm{GHz}$ bandwidth and $9.2 \mathrm{dBi}$ gain, moreover, it has a large size.

By comparison, the proposed compact planar array has a broad bandwidth of $6.8 \mathrm{GHz}$ and a simple 2D structure. More importantly, with a compact size of $98 \times 32.5 \mathrm{~mm}^{2}$, a gain of 18 $\mathrm{dBi}$ is achieved, which demonstrates that the gain of a single element can significantly enhance the array performance without increasing its size.

\section{CONCLUSION}

In this work, a broadband high-gain planar array using loop and dipole patches for $5 \mathrm{G}$ applications is proposed. With a compact size of only $98 \mathrm{~mm} \times 32.5 \mathrm{~mm}$ and a simple $2 \mathrm{D}$ geometry, the array achieved a high gain of $18 \mathrm{dBi}$ and a broad impedance bandwidth of $6.8 \mathrm{GHz}$ at $28 \mathrm{GHz}$. The good features of the planar array were demonstrated through successful comparison of its performance with existing designs in terms of bandwidth, gain, dimension, and complexity.

\section{References}

[1] IEEE International Network Generations Roadmap, https://futurenetworks.ieee.org/images/files/images/roadm ap/INGR_ExecSumm_Ed1.pdf [last access March 10, 2020].

[2] T. S. Rappaport et al., "Millimeter wave mobile communications for 5G cellular: It will work!", IEEE Access, vol. 1, pp. 335-349, 2013.

[3] W. L. Stutzman and G. A. Thiele, Antenna Theory and Design. 3rd Ed., J. Wiley \& Sons, 2012, pp. 109.

[4] J. Zhang, X. Ge, Q. Li, M. Guizani, and Y. Zhang, "5G millimeter-wave antenna array: design and challenges," IEEE Wireless Commun., vol. 24, no. 2, pp. 106-112, Apr. 2017

[5] B. Yang, Z. Yu, Y. Dong, J. Zhou, and W. Hong, "Compact tapered slot antenna array for $5 \mathrm{G}$ millimeter-wave massive MIMO systems," IEEE Trans. on Antennas and Propag., vol. 65, no. 12, pp. 6721-6727, Dec. 2017.

[6] Y. Liu, M.C.E. Yagoub, and M. Nassor, "Omni-directional antenna array with improved gain for $5 \mathrm{G}$ communication systems," in 2020 IEEE USNC-CNC-URSI North American Radio Science Meeting (Joint with AP-S Symp.), pp. 33-34, Montreal, QC, Canada, July 2020.

[7] T. Varum and J. N. Matos, "Compact slot antenna array for 5G communications," IEEE Int. Symp. Antennas Propag. and USNC-URSI Radio Science Meeting, pp. 1415-1416, Atlanta, USA, Otc. 2019.

[8] H. A. Diawuo and Y. B. Jung, "Broadband proximity coupled microstrip planar antenna array for $5 \mathrm{G}$ cellular applications," IEEE Antennas Wireless Propag. Lett., vol. 17, pp. 1286-1290, May 2018.

[9] T. Varum, A. Ramo, and J. N. Matos, "Planar microstrip series-fed array for $5 \mathrm{G}$ applications with beamforming capabilities," IEEE MTT-S Int. Microw. Workshop Series on 5G Hardware and System Techn., pp. 1-3, Dublin, Ireland, Aug. 2018.

[10] Y. Liu and M.C.E. Yagoub, "Wideband millimeter wave planner sub-array with enhanced gain for 5G communication systems," IEEE MTT-S Int. Conf. on Numerical Electromag. and Multiphy. Modeling and Optim., pp. 1-4, Hangzhou, China, Dec. 2020.

[11] Y. Liu, G. Bai and M.C.E. Yagoub, “A 79GHz series fed microstrip patch antenna array with bandwidth enhancement and sidelobe suppression," in 2020 Int. Conf. on Radar, Antenna, Microw., Electronics, and Telecomm., pp. 155-158, Tangerang, Indonesia, Nov. 2020.

[12] T. Li and F. Fan, "Design of ka-band $2 \times 2$ circular polarization slot antenna array fed by ridge gap waveguide," Sixth Asia-Pacific Conf. on Antennas and Propag., pp. 1-3, Xi'an, China, Oct. 2017.

[13] Ansys ${ }^{\circledR}$ High Frequency Structure Simulator, Release 19.1.

[14] J. Bang, Y. Hong, and J. Choi, "MM-wave phased array antenna for whole-metal-covered 5G mobile phone applications," Int. Symp. Antennas and Propag., pp. 1-2., Phuket, Nov. 2017. 
[15] R. Parthasarathy, A. Chandrasekar, and P. G. V Ramesh, "Design of Linear $2 \times 2$ Array Using Substrate-Integrated-Waveguide Patch Antenna for $28 \mathrm{GHz}$ mm-Wave Applications," TEQIP III Sponsored Int. Conf. Microwave Integrated Circuits, Photonics and Wireless Networks, pp. 44-49, Tiruchirappalli, India, May 2019.

\section{Creative Commons Attribution License 4.0 (Attribution 4.0 International, CC BY 4.0)}

This article is published under the terms of the Creative Commons Attribution License 4.0

https://creativecommons.org/licenses/by/4.0/deed.en_US 